
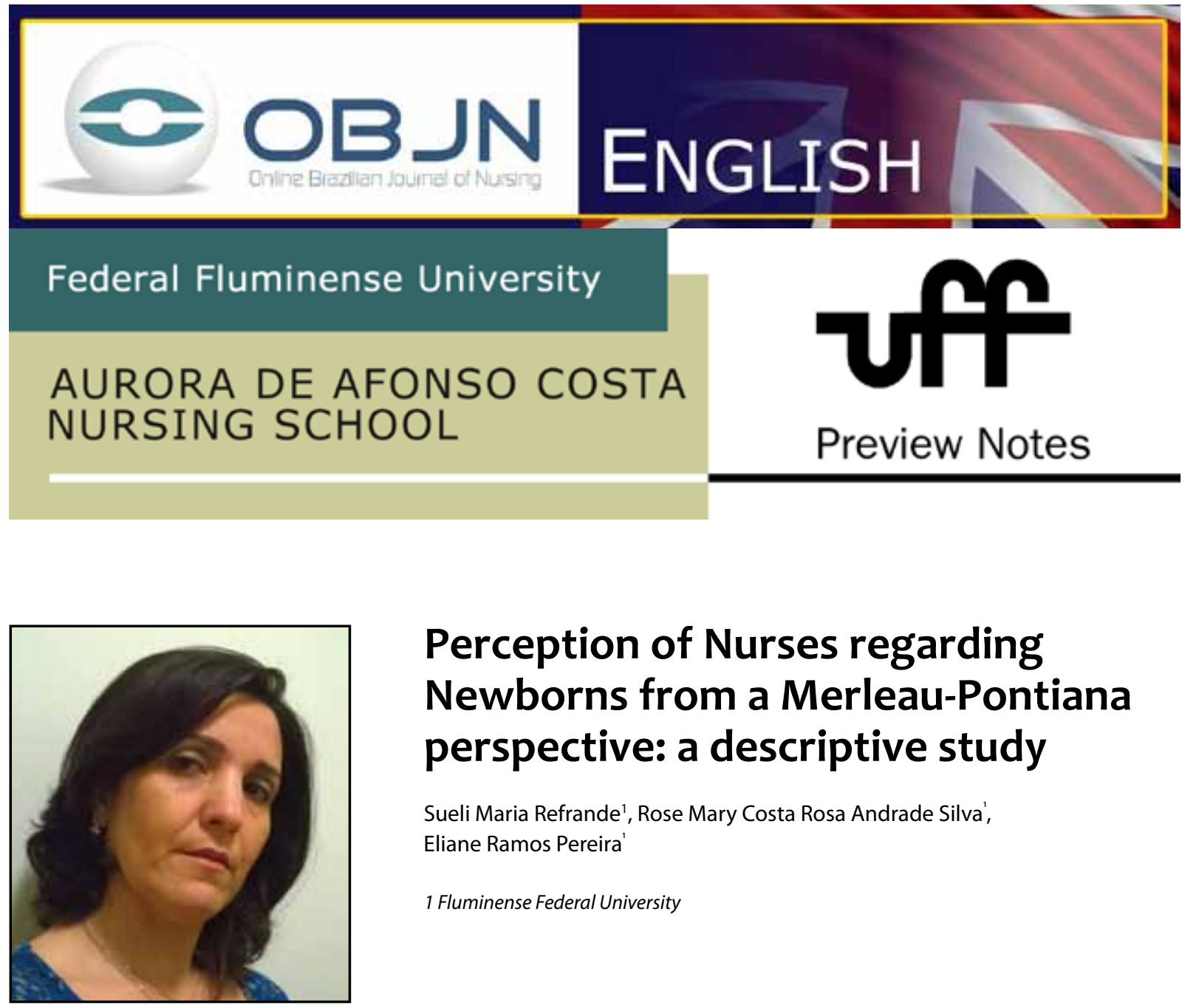

\title{
Perception of Nurses regarding Newborns from a Merleau-Pontiana perspective: a descriptive study
}

\author{
Sueli Maria Refrande', Rose Mary Costa Rosa Andrade Silva', \\ Eliane Ramos Pereira' \\ 1 Fluminense Federal University
}

\section{ABSTRACT}

Problem: The assistance to the provided by neonatal intensive care units (NICU) is a complex task involving the child, the family and the entire interdisciplinary healthcare team, especially nurses, who, in addition to their duties and daily tasks, welcome nursing graduate students and future nurses and induct them with regard to the expectations and limitations associated with performing the procedures required as part of the care process. Aims: To understand the perceptions of nurses with regard to the nursing students in terms of the high complexity care provided to newborns; to describe the experiences of nurses with graduate students in terms of the care provided to newborns at high risk. Method: This is a descriptive and phenomenological study using a qualitative approach that includes phenomenological interviews mediated by a guiding question. Interviews will be carried out with nurses at the NICU of a public institution. Discourses manifested in the statements will be evaluated in the light of the Merleau-Ponty existential phenomenological approach.

Descriptors: Students, Nursing; Child Care; Neonatology; Neonatal Nursing; Intensive Care Units. 


\section{PROBLEM SITUATION AND ITS SIGNIFICANCE}

Neonatal mortality (between zero and 27 days of life) represents about $60 \%$ to $70 \%$ of infant mortality and, therefore, major advances in the health of Brazilian children are needed, particularly with respect to newborn care $^{(1)}$. Thus the neonatal intensive care unit (NICU) is a necessary environment for the newborn's survival(2), despite being considered a hostile place with so much noise as to cause discomfort and to compromise the newborn's development. In this context, we highlight the importance of material resources as well as the development of trained and updated personnel to ensure a more qualified newborn care situation.

Such an environment triggers strong emotions and perceptions concerning life and death with regard to high risk newborns, and involves a whole interdisciplinary team, especially nurses who are most commonly present. Such professionals perform a large number of activities that are uniquely theirs, even in the presence of so much advanced technology. In addition to their duties and daily tasks, they receive nursing students and future nurses in spite of these nurses' limitations and expectations in the act of performing the necessary procedures that make up the care process.

The assistance to the newborn is aimed at curing disease, with the emphasis on the diagnosis and treatment. Limited parental and family involvement affect the interaction of professionals in the health care management process $^{(3)}$. In these circumstances, the interaction of graduate nursing students in the unit becomes complex, and can be reduced to a technical visit.

From this perspective, the student's integration into the practice setting occurs with the articulation of educational moments and care aimed at the newborn, applying all their knowledge as part of the procedures.

\section{GUIDING QUESTION}

What is the perception of nurses regarding nursing students in view of the care that has to be provided with regard to high complexity newborns in the field of clinical practice in child health?

\section{AIMS}

- To understand the perceptions of nurses concerning nursing students in view of the care that has to be provided with regard to high complexity newborns;

- To describe nurses' experience regarding students in view of the care that has to be provided with regard to high risk newborns.

\section{METHOD}

The phenomenological method associated with Merleau-Ponty will allow us to identify the essence of this situation. The study will be conducted in a NICU of a maternity hospital in the city of Rio de Janeiro. That unit comprises a population of 34 nurses, together with nursing leadership, physicians and daily workers. For sampling we will include nurses who have or have had experience in dealing with nursing students practice in the unit. Those who have only followed students in technical visits in the service will be excluded. It is estimated a sample of at least 15 participants will be used. This will enable sufficient data input for the unveiling of the 
phenomenon. After the reading and explanation of the Consent Form, data collection will be undertaken and will be interrupted only once there is a repetition of information. The interviews will occur at the within the unit and will be previously scheduled according to the availability of the subjects, allowing greater freedom and minimal interference in carrying out the meetings, considered essential factors in phenomenological research. Data will be collected after approval by the Research Ethics Committee and the accommodation of the researcher in the study scenario, and this stage is planned for the second half of 2015. The interviews will be recorded on a magnetic device and later transcribed. The identity of the participants will be preserved using fictitious names, given the ethical and legal specifications of Resolution 466/2012.

To perform the analysis of the interviews we will use the methodological procedures defined by phenomenology. Initially, the interviews will be fully and carefully read in order to grasp the global meaning, but without interpreting or identifying the attributes contained therein. Soon after, the identification and the grouping of the descriptions of each interview will be made, since they are the obvious indication of the essence of the phenomenon. After obtaining the units of meaning, the fragments of the interviews that make sense and that answer the guiding question will be identified, highlighted, examined and submitted to thematic analysis based on Merleau-Ponty's theoretical framework.

\section{REFERENCES}

1. Ministério da Saúde (Brasil), Secretaria de Atenção à Saúde, Departamento de Ações Programáticas Estratégicas. Atenção à Saúde ao Recém-Nascido: Guia para os Profissionais de Saúde Cuidados Gerais. Brasília: Ministério da Saúde; 2012.

2. Lélis ALPA, Farias LM, Rebouças CBA, Cardoso $M V L$. Health promotion and nurse facing newborn pain in the neonatal unit: an exploratory study. Online braz j nurs [internet].2010 Nov [Cited 2014 Aug 10]; 9(2). Available from: http://www.ojnursing.uff.br/index.php/nursing/article/view/2996 DOI: http://dx.doi. org/10.5935/1676-4285.20102

3. Cruz ARM, Oliveira MMC, Cardoso MVLML, Lúcio IML. Sentimentos e expectativas da mãe com filho prematuro em ventilação mecânica. Rev. Eletr. Enf. [Internet]. 2010 [cited 2010 jun 30];12(1):133-9. Available from:

4. http://www.fen.ufg.br/revista/v12/n1/pdf/ v12n1a16 DOI: http://dx.doi.org/10.5216/ree. v12i1.9530

\section{Data of the project}

Thesis project of Doctorate in Health Care Science, Fluminense Federal University, approved on February 20, 2014 by an examination board composed by the professors and doctors Rose Mary Costa Rosa Andrade Silva, Cláudia Mara de Melo Tavares and Enéas Rangel Teixeira.

\section{Ethical considerations:}

This project is part of the Umbrella project entitled: "The Symbolic Construction of Health Professionals on Humanization", approved by the Ethics Committee under the number 208.069

Advisor: Prof. Dr. Rose Mary Costa Rosa Andrade Silva

Co-advisor: Prof. Dr. Eliane Ramos Pereira

Financial Support to the Research: CAPES Scholarship 
All authors participated in the phases of this publication in one or more of the following steps, in According to the recommendations of the International Committee of Medical Journal Editors (ICMJE, 2013): (a) substantial involvement in the planning or preparation of the manuscript or in the collection, analysis or interpretation of data; (b) preparation of the manuscript or conducting critical revision of intellectual content; (c) approval of the versión submitted of this manuscript. All authors declare for the appropriate purposes that the responsibilities related to all aspects of the manuscript submitted to OBJN are yours. They ensure that issues related to the accuracy or integrity of any part of the article were properly investigated and resolved. Therefore, they exempt the OBJN of any participation whatsoever in any imbroglios concerning the content under consideration. All authors declare that they have no conflict of interest of financial or personal nature concerning this manuscript which may influence the writing and/or interpretation of the findings. This statement has been digitally signed by all authors as recommended by the ICMJE, whose model is available in http://www. objnursing.uff.br/normas/DUDE_eng_13-06-2013.pdf

Received: 08/29/2014

Revised: $11 / 06 / 2014$

Approved: $11 / 06 / 2014$ 